\title{
Speed Control of Three Phase Induction Motor Using PLC under Open and Closed Loop Condition
}

\author{
Mahesh Kumar K M*, B Ramachandra** \\ *(Department of Electrical and Electronics Engineering, PES College of Engineering, Mandya-571401 \\ ** (Department of Electrical and Electronics Engineering, PES College of Engineering, Mandya-571401
}

\begin{abstract}
In today's world industries demand process automation in all sectors, because automation results in better quality, increased production and reduced costs. The variable speed drives which can control the speed of AC/DC motors are indispensable controlling elements in automation systems. Depending on the application some of the $m$ are fixed speed and some of them are variable speed drives.

The objective of the work is to monitor and control the speed of an Induction motor under various operating conditions such as no load and on load driven by AC Drive using programmable logic controller.
\end{abstract}

Keywords: Programmable logic Controller, Open loop system, Closed Loop System, AC Drive, Ladder Logic

\section{INTRODUCTION}

The variable speed drives, till a couple of decades back, had various limitations, such as poor efficiencies, large space, lower speed etc., However, the advent of power electronic devices such as power MOSFETs, IGBTs etc., and also with the introduction of advanced PLC has transformed the scene completely. Today we have variable speed drive systems which are not only in smaller size but also very efficient, highly reliable and meeting all the stringent demands of various industries of modern era.

In any industry, the induction motor plays an important role due to its low cost and simplicity.By implementing a monitoring and control system for the speed of motor, the induction motor can be used in high performance variablespeed applications. In number of industries, motors must satisfy very strict speed requirements, both with respect to the range and smoothness of control and also with respect to economical operation. The control of equipment has been performed through the use of computers. Most equipment's use programmable logic controllers (PLC) to connect with computers to monitor each load and electricity consuming devices. A PLC interacts with the external world through its inputs and outputs

Induction Motor: The induction motor is also referred as an asynchronous motor. An induction or asynchronous electric motor is known as an Alternating current motor unit wherein the household current with in the rotor are required to create torque and is simply acquired through electromagnetic induction through the magnetic field with the stator turning. An induction motor consequently doesn't require physical commutation, separate-excitation or self-excitation. An induction motor's rotor could be of two types,

$>$ Squirrel-cage rotor

$>$ Slip ring or phase wound rotor

There are generally two kinds of induction motor which rely upon the particular input supply, which are

$>$ Single phase induction motor

$>$ Three phase induction motor

Three-phase induction motors are more commonly employed in adjustable-speed drives than three-phase synchronous motors. Stator windings of both types carry three-phase windings. Rotor of SCIM is made of copper or aluminium bars shortcircuited by two end rings. Rotor of SRIM carries three-place winding connected to three s lip rings on the rotor shaft.

Electric Drives: An Electric Motor together with its control equipment and energy transmitting device forms an electric drive. An electric drive together with its working machine constitutes an electric drive system.

Programmable logic controller (PLC): PLC is a special form of microprocessor-based controller that uses programmable memory to store instructions and to implement functions such as logic, sequencing, timing, counting, and arithmetic in order to control machines and processes.

\section{LITERATURE SURVEY}

The different papers published on speed control of induction motor are: 
[1] Microcontroller based speed control of three phase induction motor using v/f method: Induction motors are widely used AC motors in industrial area. Advanced semiconductor technology $\&$ use of microcontroller have made the speed control of induction motor easier. The work makes use of DSPIC30F2010 microcontroller, in order to operate induction motor using $\mathrm{V} / \mathrm{F}$ method. The various factors which make the microcontroller based system attractive are, 1 . Improved reliability and increased flexibility. 2. Simplicity of implementation in variable speed drives 3 . Low cost and high accuracy 4. Possible to change torque speed characteristics of drive by software modification. The simplicity of this project is that it can be operate by any person who need not know microcontroller programming.

[2] V/F Speed Control of 3 phase Induction Motor using Space Vector Modulation: The speed control of three phase induction motor is essential because the motor control industry is a dominant sector. To remain competitive, new products must be developed having several design aspects such as, cost reduction, low power consumption \& improved power factor. A number of Pulse width modulations (PWM) scheme is used to obtain variable voltage and frequency supply from an inverter, such as Sine wave Pulse Width Modulation (SPWM), Third Harmonic Pulse Width Modulation (THPWM) and Space Vector Pulse Width Modulation(SVPWM).

There is an increasing trend of using space vector PWM (SVPWM) because of their easier digital realization, better dc bus utilization and output voltage is more closed to sinusoidal wave. This paper aims at study of v/f speed control technique for Induction Motor using Space Vector Pulse Width Modulation technique with stepwise understanding of $\mathrm{v} / \mathrm{f}$ speed control method for three phase induction motor and space vector modulation and its realization by using MATLAB/SIMULINK model for two level inverter.

\section{[3] Speed Control of a Three Phase Induction Motor Using PWM Inverter:}

There are different methods of speed control of three phase induction motor and to control the speed of three phase induction motor generally using V/F control strategy. Out of the a number of methods of speed control of an induction such as pole changing, frequency variation, variable rotor resistance, variable stator voltage, constant V/f control, slip recovery method etc., the constant V/f speed control method is the majority generally used. In this method, the V/f ratio is kept constant which in turn maintains the magnetizing flux constant so that the maximum torque remains unchanged.
The simulation work proves the idea of V/F control using PWM inverter and the software used for simulation is PSIM (Powersim).The performance of the volt per hertz strategy were evaluated through simulation shown in results. In constant V/F control, by use PWM inverter, we can vary the supply voltage as well as the supply frequency such that the V/F ratio remains constant so that the flux remains constant too. So, we can get different operating zone for various speeds and torques and also we can get different synchronous speed with almost same maximum torque. Thus the motor is fully utilized and also we have a good variety of speed control. It is effortless, cost-effective to easier to design in open loop. But the drawbacks of open loop is it doesn't correct the change in output also it doesn't reach the steady state quickly.

\section{PROPOSED WORK}

Many projects have been done in order to improve the performance of three phase induction motors by controlling the speed of induction motor by various methods like sensor -based control of three phase induction motor, speed control of induction motor using PWM inverter technique, speed control of induction motor using space vector model etc.

Due to multi- variable, highly non- linear, unavailability of measurements, complexity involving the mathematical modelling, is still a difficult and complex engineering problem. PLC method of control had replaced traditional control method which improves greatly dynamic control efficiency of motor. The Programmable logic controller can simultaneously evaluate data at a faster rate thus increasing the efficiency of the motor and resulting in its better performance.

The objective of our work is to monitor the speed of a three phase induction motor under various operating conditions such as no load and on load. The motor control is attempted with a Programmable logic controller, to realize in open loop and closed loop operation under various operating conditions.

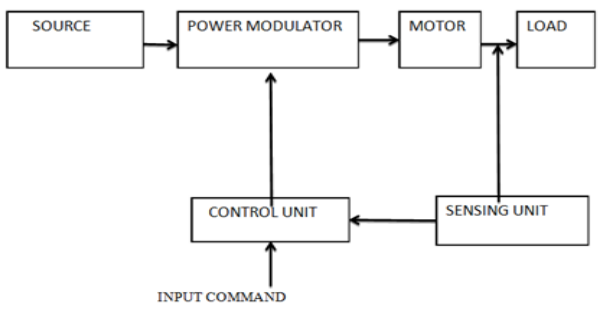

Figure shows Block Diagram of Electric Drive 
Types of Electric Drives: Electric drives are mainly of two types: DC drives and AC drives The two types differ from each other, in that the motive power in DC and AC drives is provided by DC and AC motors respectively. For induction motor control AC Drive is used in our work.

AC Drives: AC drives, inverters, and adjustable frequency drives are all terms that are used to refer to equipment designed to control the speed of an AC motor.AC drives receive $\mathrm{AC}$ power and convert it to an adjustable frequency, adjustable voltage output for controlling motor operation. All AC drives convert $\mathrm{AC}$ to $\mathrm{DC}$, and then through various switching techniques invert the DC into a variable voltage, variable frequency output.

AC drives have been used in the past mainly in application requiring a constant speed because conventional methods of the speed control have either been expensive or highly inefficient.

There are two types of ac drives:

- Induction motor drives

- Synchronous motor drives

Speed Control Techniques Employed In Induction Motor Drives:

\section{- From Stator side}

1. V/f control or frequency control.

2. Changing the number of stator poles.

3. Controlling supply voltage.

4. Adding rheostat in the stator circu it.

\section{- From Rotor side}

1. Adding external resistance on rotor side.

2. Cascade control method.

3. Injecting slip frequency emf into rotor side.

A programmable logic controller (PLC): is a special form of microproces sor-based controller that uses programmable memory to store instructions and to implement functions such as logic, sequencing, timing, counting, and arithmetic in order to control machines and processes. It is designed to be operated by engineers with perhaps a limited knowledge of computers and computing languages. They are not designed so that only computer programmers can set up or change the programs. Thus, the designers of the PLC have preprogrammed it so that the control program can be entered using a simple, rather intuitive form of language. The result is a flexible, cost-effective system that can be used with control systems, which vary quite widely in their nature and complexity. PLCs are similar to computers, but whereas computers are optimized for calculation and display tasks, PLCs are optimized for control tasks and the industrial environment. Thus PLCs are rugged and designed to withstand vibrations, temperature, humidity, and noise and Have interfacing for inputs and outputs already inside the controller

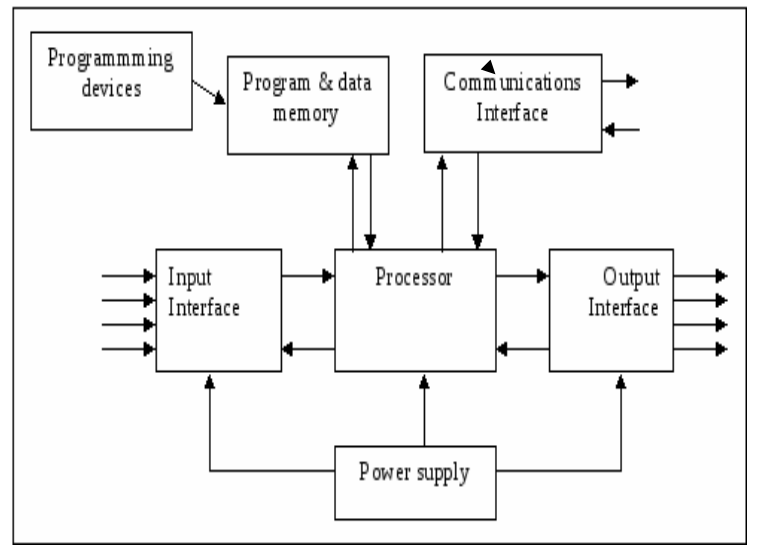

Figure 2: PLC Block Diagram

The CPU: The internal structure of the CPU depends on the microprocessor concerned. In general,CPUs have the following: An arith metic and logic unit (ALU) that is responsible for data manipulation and carrying out arithmetic operations of addition and subtraction and logic operations of AND, OR, NOT, and EXCLUSIVE-OR.

The Buses: The buses are the paths used for communication within the PLC. The information is transmitted in binary form, that is, as a group of bits, with a bit being a binary digit of 1 or 0 , indicating on/off states.

The data bus carries the data used in the processing done by the CPU. The address bus is used to carry the addresses of memory locations. So that each word can be located in memory, every memory location is given a unique address. If the address bus consists of eight lines, the number of 8-bit words, and hence number of distinct addresses, is 256 . With 16 address lines, 65,536 addresses are possible.

The control bus carries the signals used by the CPU for control, such as to inform memory devices whether they are to receive data from an input or output data and to carry timing signals used to synchronize actions.

Memory: To operate the PLC system there is a need for it to access the data to be processed and instructions, that is, the program, which informs it how the data is to be processed. Both are stored in the PLC memory for access during processing. There are several memory elements in a PLC system. Read-only-me mory (ROM) gives permanent storage for the operating system and fixed data used by the CPU.

Random-access memory (RAM) is used for the user's program. Random-access memory (RAM) is used for data. 
Input /Output Unit: The input/output unit provides the interface between the system and the outside world, allowing for connections to be made through input/output channels to input devices such as sensors and output devices such as motors and solenoids. It is also through the input/output unit that programs are entered from a program panel.

Programming PLCs: A programming device can be a handheld device, a desktop console, or a computer. Only when the program has been designed on the programming device and is ready is it transferred to the memory unit of the PLC. A handheld programming device normally contains enough memory to allow the unit to retain programs while being carried from one place to another.

Desktop consoles are likely to have a visual display unit with a full keyboard and screen. Personal computers are widely configured as program development workstations. Some PLCs only require the computer to have appropriate software; others require special communication cards to interface with the PLC. A major advantage of using a computer is that the program can be stored on the hard disk or a CD and copies can be easily made.

A very commonly used method of programming PLCs is based on the use of ladder diagrams. Writing a program is then equivalent to drawing a $s$ witching circu it. The ladder diagram consis ts of two vertical lines representing the power rails. Circuits are connected as horizontal lines, that is, the rungs of the ladder, between these two verticals.

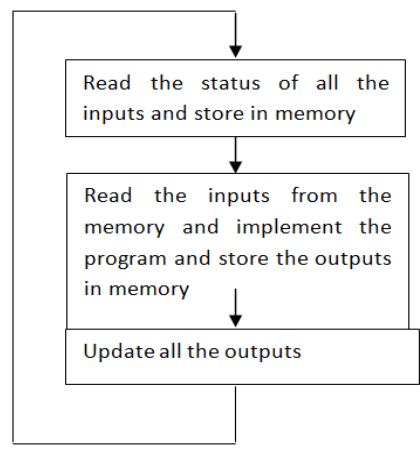

Figure 4: Scanning the ladder diagram

IV. RESULTS AND DISCUSSIONS

4.1 Block \& connection di agram

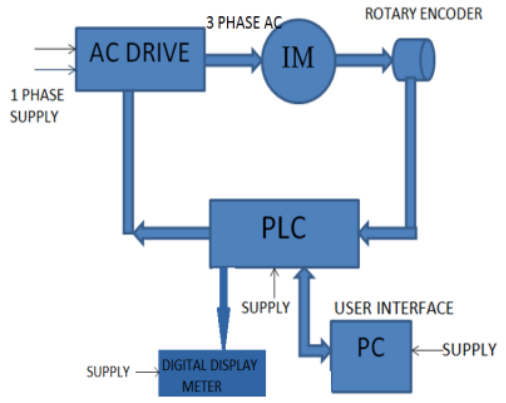

Figure 5: Block Diagram for Induction motor Speed Monitoring

Figure 5 show complete block diagram of project.

The various components of our project are:

- 3 phase induction Motor

- ACdrive

- PLC

- PC as an user Interface

- Encoder for feedback input(rotary type)

- Dig ital display meter

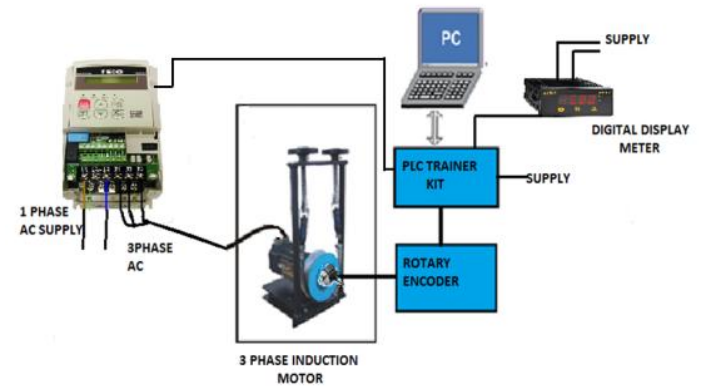

Figure 6.Connection Diagram

The motor can be operated both in open loop and closed loop condition. In closed loop condition the feedback signal is obtained through encoder connected to motor output shaft which makes it possible for the actual speed of the motor to catch the set speed. However, in open loop the actual speed cannot catch the set speed due to lack of feedback signal.

\subsection{Ladder Logic:}

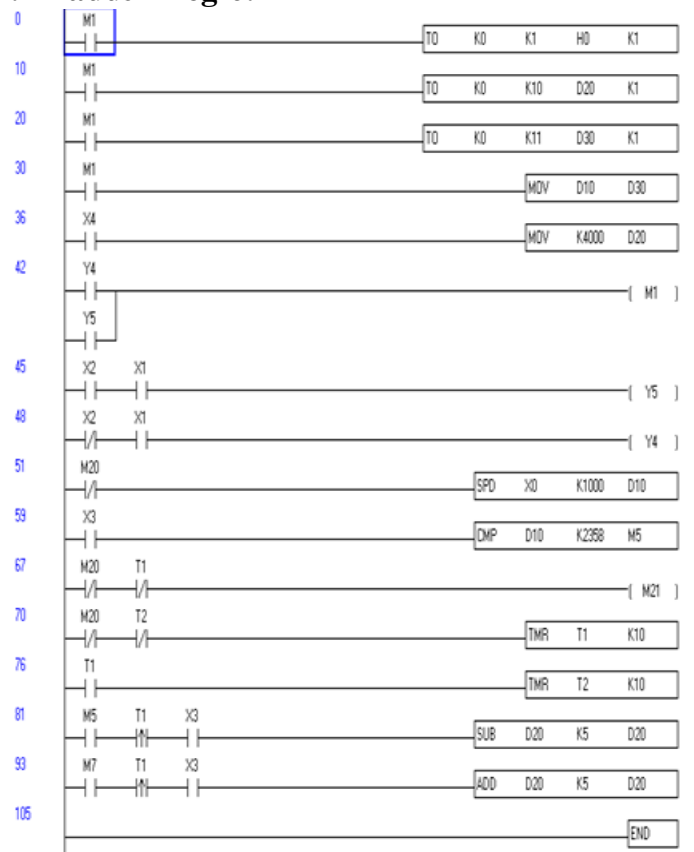




\subsection{No Load Conditions}

4.3.1 Forward direction under no load condition

\begin{tabular}{|l|l|l|l|}
\hline $\begin{array}{l}\text { SET } \\
\text { SPEED } \\
(\mathbf{r p m})\end{array}$ & $\begin{array}{l}\text { FREQUE } \\
\text { NCY } \\
(\text { HZ) }\end{array}$ & $\begin{array}{l}\text { OPEN } \\
\text { LOOP } \\
\text { SPEED } \\
(\mathbf{r p m})\end{array}$ & $\begin{array}{l}\text { CLOSE } \\
\text { LOOP } \\
\text { SPEED } \\
(\mathbf{r p m})\end{array}$ \\
\hline 100 & 3.54 & 103 & 98 \\
\hline 200 & 7.05 & 209 & 198 \\
\hline 300 & 10.59 & 313 & 298 \\
\hline 400 & 14.1 & 419 & 400 \\
\hline 500 & 17.63 & 523 & 500 \\
\hline 600 & 21.13 & 629 & 600 \\
\hline 700 & 24.66 & 734 & 699 \\
\hline 800 & 28.17 & 838 & 800 \\
\hline 900 & 31.69 & 943 & 899 \\
\hline 1000 & 35.25 & 1048 & 994 \\
\hline 1100 & 38.76 & 1154 & 1100 \\
\hline 1200 & 42.27 & 1259 & 1192 \\
\hline 1300 & 45.88 & 1364 & 1300 \\
\hline 1400 & 49.31 & 1469 & 1394 \\
\hline 1415 & 49.83 & 1484 & 1415 \\
\hline
\end{tabular}

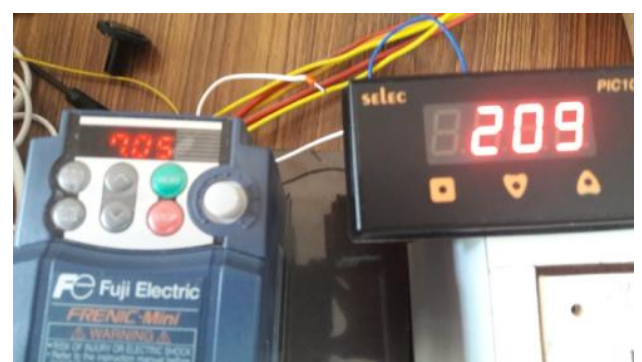

(a)

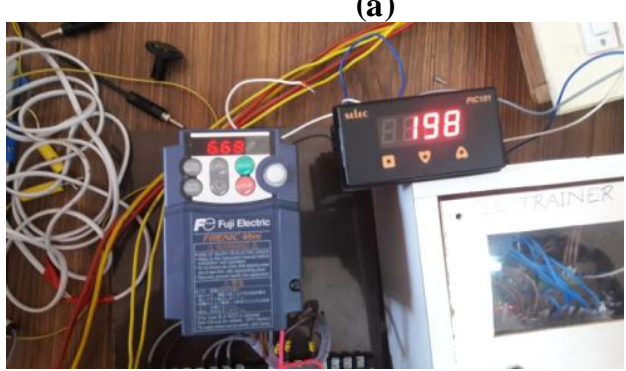

(b)

Figure 6: (a) Open Loop Operation (b) Closed Loop Operation for forward direction in no load condition for a set speed of 200

4.3.2 for reverse direction under no load condition

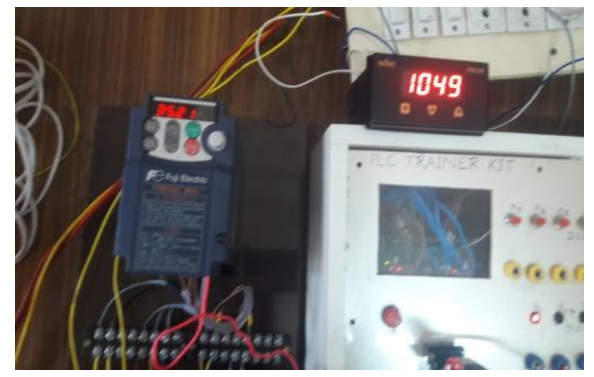

(a)

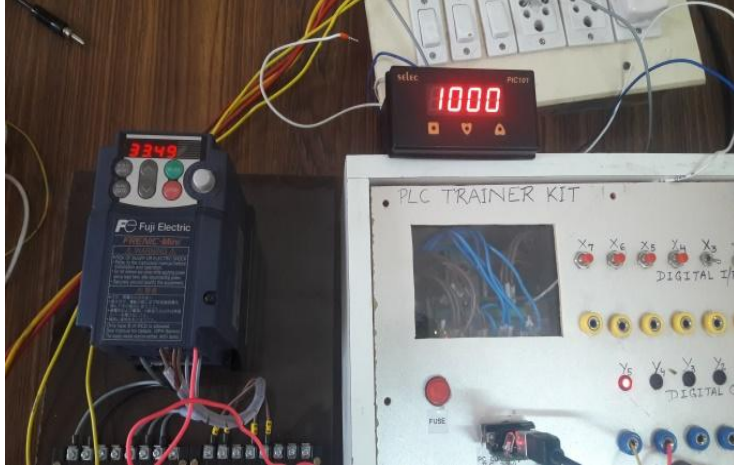

(b)

Figure 7: (a) Open Loop Operation (b) Closed Loop Operation for reverse direction in no load condition for a set s peed of 1000

\begin{tabular}{|l|l|l|l|}
\hline $\begin{array}{l}\text { SET } \\
\text { SPEED } \\
(\mathbf{r p m})\end{array}$ & $\begin{array}{l}\text { FREQU } \\
\text { ENCY } \\
(\text { HZ) }\end{array}$ & $\begin{array}{l}\text { OPEN } \\
\text { LOOP } \\
\text { SPEED } \\
\text { (rpm) }\end{array}$ & $\begin{array}{l}\text { CLOSE } \\
\text { LOOP } \\
\text { SPEED } \\
(\mathbf{r p m})\end{array}$ \\
\hline 100 & 3.54 & 104 & 98 \\
\hline 200 & 7.05 & 209 & 198 \\
\hline 300 & 10.59 & 314 & 298 \\
\hline 400 & 14.11 & 419 & 400 \\
\hline 500 & 17.61 & 523 & 500 \\
\hline 600 & 21.13 & 629 & 600 \\
\hline 700 & 24.66 & 734 & 700 \\
\hline 800 & 28.17 & 838 & 800 \\
\hline 900 & 31.69 & 943 & 899 \\
\hline 1000 & 35.21 & 1049 & 1000 \\
\hline 1100 & 38.75 & 1154 & 1100 \\
\hline 1200 & 42.27 & 1259 & 1198 \\
\hline 1300 & 45.79 & 1364 & 1297 \\
\hline 1400 & 49.31 & 1469 & 1398 \\
\hline 1415 & 49.85 & 1484 & 1413 \\
\hline
\end{tabular}

4.4 Loading condition

4.4.1 Forward direction under load condition

\begin{tabular}{|l|l|l|}
\hline $\begin{array}{l}\text { LOAD } \\
\text { L1+L2(Kg) }\end{array}$ & $\begin{array}{l}\text { OPEN LOOP } \\
\text { SPEED (rpm) }\end{array}$ & $\begin{array}{l}\text { CLOSE } \\
\text { LOOP } \\
\text { SPEED } \\
\text { (rpm) }\end{array}$ \\
\hline $2.1+0.4=2.5$ & 356 & 352 \\
\hline $3.6+0.6=4.2$ & 335 & 351 \\
\hline $4.4+0.8=5.2$ & 324 & 352 \\
\hline $4.8+0.8=5.6$ & 307 & 351 \\
\hline
\end{tabular}

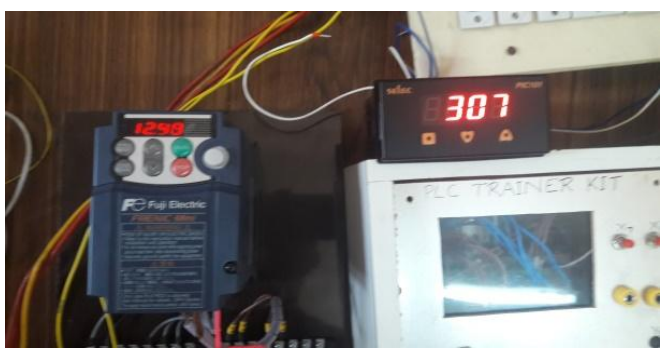

(a) 


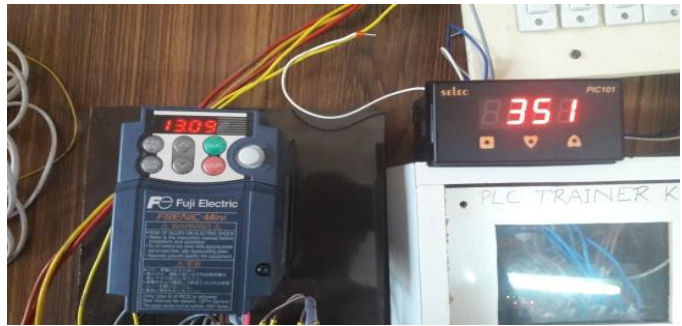

(b)

Figure 8: (a) Open Loop Operation (b) Closed Loop Operation for forward direction in load condition

4.4.2 Reverse direction under load condition

\begin{tabular}{|l|l|l|}
\hline $\begin{array}{l}\text { LOAD } \\
\text { L1+L2 } \\
(\mathrm{Kg})\end{array}$ & $\begin{array}{l}\text { OPEN } \\
\text { LOOP } \\
\text { SPEED } \\
\text { (rpm) }\end{array}$ & $\begin{array}{l}\text { CLOSE } \\
\text { LOOP } \\
\text { SPEED } \\
\text { (rpm) }\end{array}$ \\
\hline $\mathbf{0 . 6 + 0 . 6 = 1 . 2}$ & 1481 & 1406 \\
\hline $1.5+0.9=2.4$ & 1473 & 1407 \\
\hline $2.5+1.2=3.7$ & 1462 & 1406 \\
\hline $3.8+1.7=55$ & 1450 & 1409 \\
\hline
\end{tabular}

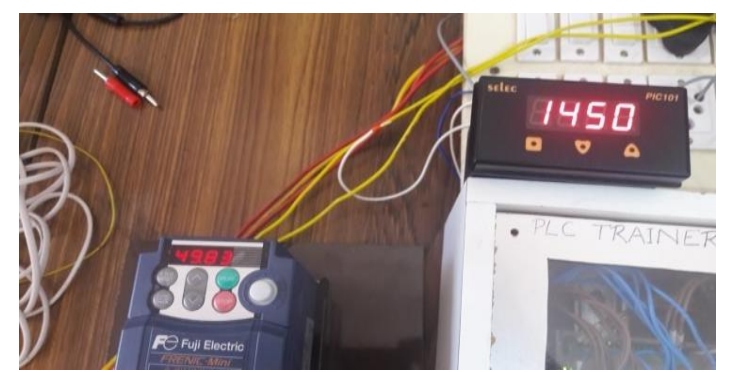

(a)

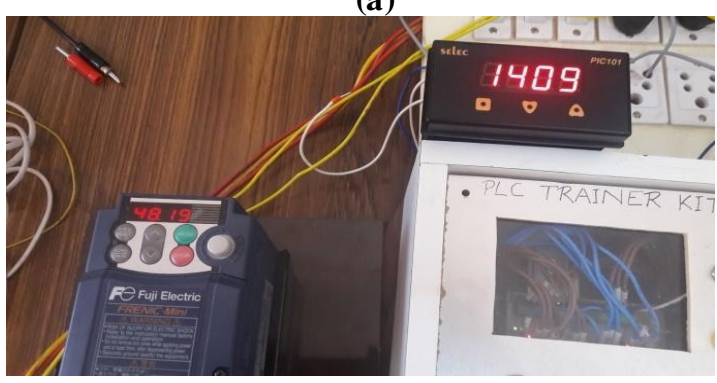

(b)

Figure 9: (a) Open Loop Operation (b) Closed Loop Operation for reverse direction in load condition for a set speed of $1415 \mathrm{rpm}$ theoretically

\section{V.CONCLUSIONS}

The developed hardware and software has been tested for its validity under various operating conditions. We observed that both the hardware and software coordinated and were in close relation.

To validate, the drive has been tested for various operating conditions. Under closed loop condition when the input command is set to a speed of 1415 RPM the output speed recorded will be around 1406 RPM (in digital display meter). Experiments were repeated for different speeds and results were found to be closed to the set value.

\section{VI.FUTURE ENHANCEMENT}

Motor speed can be controlled and multiple motors can also be controlled with required modification in the software and Torque control can be implemented.

\section{REFERENCE}

[1]. Ahmed, Irfan (ed.). [1991]. Digital Control Applications With the TMS320 Family, Texas Instruments, Dallas, TX, 1991.

[2]. J.R. Hendershot, Jr. and T.J.E. Miller, Design of three phase Induction Motors, Magna Physics Publishing and Clarendon Press, Oxford, U.K., 1994.

[3]. Microcontroller based speed control of three phase induction motor using v/f method. International Journal of Scientific and Research Publications, Volume 3, Issue 2, February 2013

[4]. V/F Speed Control of 3 phase Induction Motor using Space Vector Modulation

[5]. by Ms.Priya Subhash Raichurkar, International Journal of Engineering Research \& Technology

[6]. T. Kenjo and S. Nagamori, Three phase induction Motors, Clarendon Press, Oxford,U.K., 1985.

[7]. Three phase induction motor speed controller using PLC approach by Yogini B. Hirave, Prof. R.T. Patil, Mrs KetanBagade, International Journal of Engineering Science Invention.

[8]. Programmable logic controllers, $5^{\text {th }}$ editionW Bolton.

[9]. Power Electronics-Dr P S Bimbhra. 